\title{
Inhibition of Ras-GTPase Improves Diabetes-Induced Abnormal Vascular Reactivity in the Rat Perfused Mesenteric Vascular Bed
}

\author{
Mariam H.M. Yousif ${ }^{a} \quad$ Ibrahim F. Benter $^{a}$ Saju Abrahama Saghir Akhtar ${ }^{b}$ \\ a Department of Pharmacology and Toxicology, Faculty of Medicine, Kuwait University, Kuwait; \\ ${ }^{b}$ Centre for Genome-Based Therapeutics, Welsh School of Pharmacy, Cardiff University, Cardiff, UK
}

\section{Key Words}

Diabetes · Ras-GTPase • Norepinephrine · Endothelin-1 •

Angiotensin II - Carbachol · Histamine $\cdot$ Mesenteric bed

\begin{abstract}
Objective: The signalling mechanisms involved in regulating altered vascular reactivity in diabetes are not fully understood. The aim of this study was to investigate the role of Ras-GTPase in the development of abnormal vascular reactivity in diabetes. Materials and Methods: We investigated the ability of chronic administration of FPTIII $(1.5 \mathrm{mg} / \mathrm{kg})$, an inhibitor of Ras-GTPase, to modulate the altered vasoreactivity of the rat perfused mesenteric bed to common vasoconstrictors and vasodilators in streptozotocin (STZ)-induced diabetes. Results: The vasoconstrictor responses induced by norepinephrine (NE) and endothelin-1 (ET-1) were significantly increased whereas vasodilator responses to carbachol, histamine and isoprenaline were significantly reduced in the perfused mesenteric bed of the STZ-diabetic rats. Inhibition of Ras-GTPase by chronic administration of FPTIII produced a significant normalization of the altered agonistinduced vasoconstrictor and vasodilator responses without affecting blood glucose levels. Inhibition of RasGTPase did not affect the agonist-induced vasoconstrictor and vasodilator responses in the control animals.
\end{abstract}

Conclusion: These data suggest that signal transduction pathways activated by Ras-GTPase are involved in the development of diabetic vascular dysfunction. Potential strategies aimed at modifying actions of signal transduction pathways involving Ras-GTPase may therefore prove to be beneficial in treatment of vascular complications in diabetes.

Copyright $@ 2004$ S. Karger AG, Basel

\section{Introduction}

Cardiovascular disease is the leading cause of mortality in patients with diabetes [1]. Diabetes mellitus-induced complications such as alterations in the reactivity of blood vessels can lead to cardiovascular dysfunction including hypertension, atherosclerosis, microangiopathy and congestive heart failure [1,2]. This subsequently results in almost three times higher mortality from cardiovascular disease in diabetic patients than in the general population [1, 2]. Enhanced vascular responsiveness to vasoconstrictors and an attenuated response to vasodilators in diabetic vascular tissues have been reported previously [3-7]. However, the signalling mechanisms involved in regulating altered vascular reactivity in diabetes are not fully understood.

\section{KARGER \\ Fax +4161306 1234 \\ E-Mail karger@karger.ch \\ www. karger.com

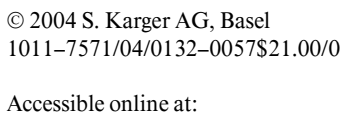

Dr. M.H.M. Yousif

Department of Pharmacology and Toxicology

Faculty of Medicine, Kuwait University

PO Box 24923, 13110 Safat (Kuwait)

Tel. +965 5312300, ext.6338, Fax +965 5342583, E-Mail mariam@hsc.kuniv.edu.kw 
FPTIII has been established as a specific inhibitor of Ras-GTPase farnesyltransferase using both in vivo and in vitro studies [8-13]. In experimental models of hypertension, we have shown that activation of the Ras-GTPasemediated signal transduction pathways leads to the development of hypertension and related end-organ pathologies, which can be prevented with FPTIII treatment [812]. In this study, we investigated the role of Ras-GTPase in the development of abnormal vascular reactivity in diabetes. In the perfused mesenteric vascular beds of rats with streptozotocin (STZ)-induced diabetes, inhibition of Ras-GTPase by FPTIII normalized the altered vascular reactivity observed with the vasoconstrictors norepinephrine (NE), endothelin-1 (ET-1) and angiotensin II (Ang II), and to the vasodilators carbachol and histamine in diabetic animals. Thus, our findings suggest that RasGTPase is involved in signalling pathways leading to abnormal vascular reactivity in diabetes.

\section{Materials and Methods}

\section{Induction of Diabetes and Treatment with FPTIII}

Female Wistar rats weighing 200-250 g were used in this study. Diabetes was induced by a single intraperitoneal injection of $55 \mathrm{mg} /$ $\mathrm{kg}$ body weight STZ dissolved in citrate buffer ( $\mathrm{pH} 4.5$ ). Agematched control rats were injected with the citrate buffer vehicle used to dissolve STZ. Body weight and basal glucose levels were determined prior to STZ injection, using an automated blood glucose analyser (glucometer Elite XL). Blood glucose concentrations were determined $48 \mathrm{~h}$ after STZ injection. Rats with a blood glucose concentration above $300 \mathrm{mg} / \mathrm{dl}$ were declared diabetic. The animals' body weights and the diabetic state were reassessed 4 weeks after STZ injection before sacrificing the animals. There were no deaths among the experimental animals and diabetic animals were not treated with insulin during the 4 weeks prior to sacrifice.

Four groups of rats were used in this study: group I - untreated control rats $(\mathrm{n}=10)$; group II - control rats that received treatment with the Ras-GTPase inhibitor FPTIII $1.5 \mathrm{mg} / \mathrm{kg}(\mathrm{n}=10)$; group III STZ-diabetic rats without treatment $(\mathrm{n}=10)$, and group IV - diabetic rats that received treatment with the Ras-GTPase inhibitor FPTIII $1.5 \mathrm{mg} / \mathrm{kg}(\mathrm{n}=8)$. FPTIII treatment was administered intraperitoneally every other day for 4 weeks starting from day 1 of diabetes induction. This dose was selected based on our previous observations in rats where we were able to normalize elevated levels of Ras-GTPase in animal models of hypertension $[8,9]$.

\section{Isolation of the Mesenteric Vascular Bed}

The mesenteric beds were isolated and transferred into a Petri dish containing oxygenated Krebs' solution. The mesenteric artery was cannulated, using a polyethylene cannula and the mesenteric bed was placed in a warm water-jacketed chamber at $37^{\circ} \mathrm{C}$. The preparation was perfused with Krebs' solution at $37^{\circ} \mathrm{C}$, oxygenated with $95 \%$ oxygen and $5 \%$ carbon dioxide, delivered at a constant flow rate of $6 \mathrm{ml} / \mathrm{min}$ using a multichannel Masterflex peristaltic pump. The composition of $\mathrm{KH}$ solution was as follows $(\mathrm{m} M)$ : $\mathrm{NaCl}$ (118.3), $\mathrm{KCl}$
(4.7), $\mathrm{CaCl}_{2}$ (2.5), $\mathrm{MgSO}_{4}$ (1.2), $\mathrm{NaHCO}_{3}(25), \mathrm{KH}_{2} \mathrm{PO}_{4}$ (1.2) and glucose (11.2). Changes in perfusion pressure which reflect peripheral resistance were measured. Perfusion pressure was recorded via a pressure transducer connected to a Lectromed recorder. The preparation was always allowed to equilibrate for at least $30 \mathrm{~min}$. A bolus injection of $100 \mathrm{nmol} \mathrm{NE}$ was usually given at the beginning of the experiment as a test for tissue responsiveness. All animal studies were approved by our institutional committee for the care and use of animals in research and education.

\section{Vasoconstriction Studies}

The vasoconstrictor responses of NE (10, 100 and 1,000 nmol), ET-1 $(0.01,0.1$ and $1.0 \mathrm{nmol})$ and Ang II $(0.1$ and $1.0 \mathrm{nmol})$ were investigated in the perfused mesenteric vascular bed. Following the period of equilibration, successive doses of the agonists NE, ET-1 or Ang II were given at regular intervals to establish the vasoconstrictor responses $(\mathrm{mm} \mathrm{Hg})$.

\section{Vasodilation Studies}

The vasodilator responses of carbachol, histamine, isoprenaline and sodium nitroprusside (SNP) were investigated in the perfused mesenteric vascular bed. Following the period of equilibration, the perfused mesenteric bed was constricted by perfusion with Krebs' solution containing NE $\left(10^{-5} M\right)$. After establishing a steady level of precontraction, successive doses of carbachol ( 1 and $10 \mathrm{nmol})$, histamine (10 and $100 \mathrm{nmol})$, isoprenaline (10 and $100 \mathrm{nmol})$ and SNP $(0.1,1.0$ and $10 \mathrm{nmol})$ were given at regular intervals. The vasodilator response is expressed as a percentage of the precontraction induced by NE $\left(10^{-5} M\right)$.

\section{Drugs}

NE-bitartrate, STZ, FPTIII, SNP, histamine, isoprenaline hydrochloride, ET-1, Ang II, and carbachol were obtained from Sigma Biochemicals.

\section{Statistical Analysis}

Results were analysed using Graph-pad (Prism software). Data are presented as mean \pm SE of ' $n$ ' number of experiments. Mean values were compared using analysis of variance followed by post hoc test (Bonferroni). A difference was considered to be significant when the $\mathrm{p}$ value was less than 0.05 . A single asterisk $\left({ }^{*}\right)$ indicates values significantly different from non-diabetic controls and double asterisk $(* *)$ indicates values significantly different from diabetic controls.

\section{Results}

\section{Hyperglycaemia and Animals' Body Weights}

Induction of diabetes by STZ resulted in a significant increase in blood glucose concentration. Hyperglycaemia persisted in the diabetic animals and was $600 \pm 18 \mathrm{mg} / \mathrm{dl}$ at 4 weeks compared to $95 \pm 3 \mathrm{mg} / \mathrm{dl}$ in the control animals. There was a significant reduction in the STZ-diabetic rats' weights compared to the control animals (160 \pm 3 and $234 \pm 12.5 \mathrm{~g}$, respectively, $\mathrm{p}<0.05)$. FPTIII treatment did not reverse the weight loss in diabetic rats, resulting in mean animal weights of $159 \pm 8 \mathrm{~g}$ after 4 


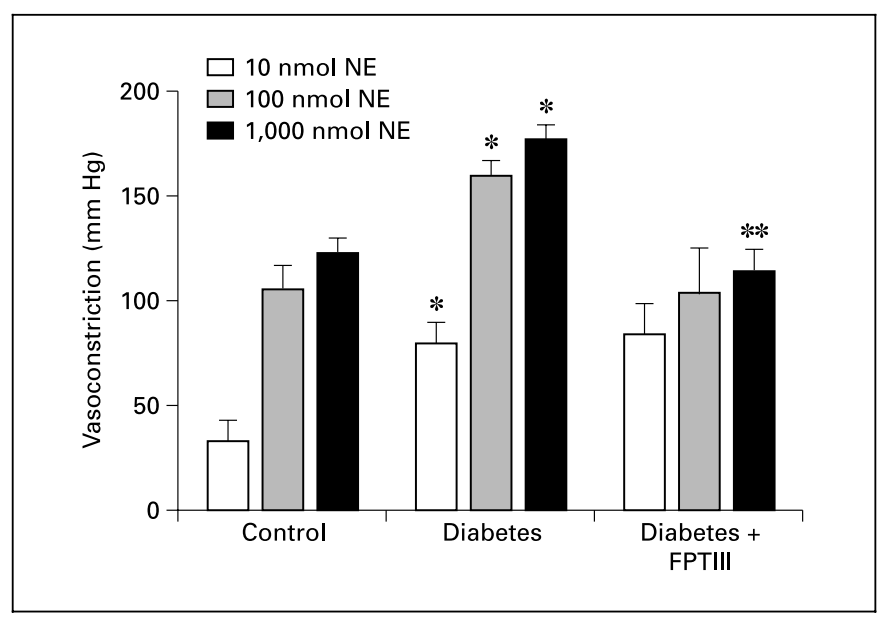

Fig. 1. NE-induced vasoconstriction $(10,100$ and 1,000 nmol) in the perfused mesenteric vascular bed of control, diabetic and FPTIIItreated diabetic rats (mean $\pm \mathrm{SE}, \mathrm{n}=8-10$ ). Mean values were compared using analysis of variance followed by post hoc test (Bonferroni). (* Significantly different from control, ${ }^{* *}$ significantly different from diabetic.)

weeks of treatment. In addition, blood glucose concentration, $604 \pm 15 \mathrm{mg} / \mathrm{dl}$, was also unaffected by 4 weeks of FPTIII treatment.

\section{Vasoconstriction Studies}

The vasoconstrictor response to NE was significantly augmented in the perfused mesenteric vascular bed from STZ-diabetic rats to $158 \pm 6$ and $178.5 \pm 6.8 \mathrm{~mm} \mathrm{Hg}$ compared to $103.9 \pm 9.5$ and $126.1 \pm 7.2 \mathrm{~mm} \mathrm{Hg}$ in the control rats, at 100 and $1,000 \mathrm{nmol}$, respectively (fig. 1). The potentiated vasopressor activity of NE was significantly reversed by 4-week treatment of diabetic rats with FPTIII $(\mathrm{p}<0.05)$. A significant reversal of NE-induced vasoconstriction due to FPTIII treatment was to $115.0 \pm$ $8.9 \mathrm{~mm} \mathrm{Hg}(\mathrm{p}<0.05)$ observed at the dose of $1,000 \mathrm{nmol}$ (fig. 1).

ET-1-induced vasoconstriction was significantly augmented in the diabetic rat perfused mesenteric bed $(p<$ 0.05). ET-1-induced vasoconstriction was $138.9 \pm 11.5$ and $199.5 \pm 7.5 \mathrm{~mm} \mathrm{Hg}$ in the diabetic mesenteric bed compared to $73.5 \pm 13.6$ and $97.9 \pm 7.5 \mathrm{~mm} \mathrm{Hg}$ at 0.1 and $1.0 \mathrm{nmol}$, respectively, in group I non-diabetic rats (fig. 2). FPTIII treatment produced a reduction in ET-1induced vasoconstriction, which was significantly different at the dose of $1.0 \mathrm{nmol}$, giving a value of $143.8 \pm$ $21.1 \mathrm{~mm} \mathrm{Hg}(\mathrm{p}<0.05)$.

Role of Ras-GTPase in Diabetes-Induced Vascular Dysfunction

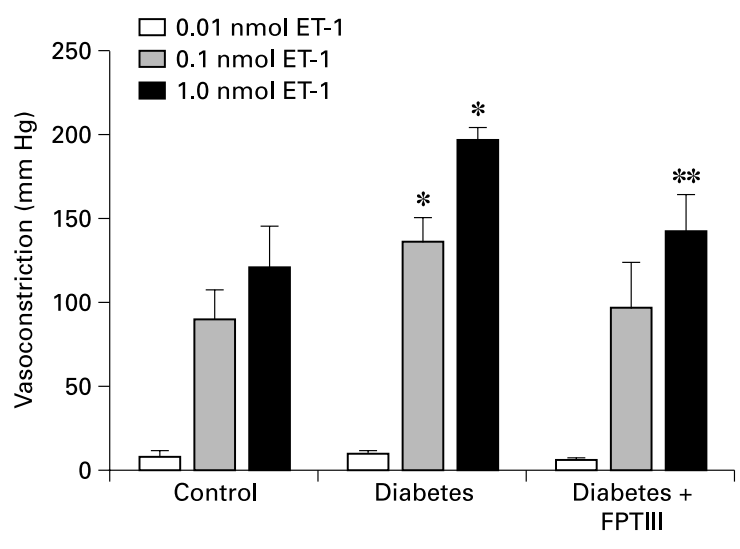

Fig. 2. ET-1-induced vasoconstriction $(0.01,0.1$ and $1.0 \mathrm{nmol})$ in the perfused mesenteric vascular bed of control, diabetic and FPTIIItreated diabetic rats (mean $\pm \mathrm{SE}, \mathrm{n}=8-10)$. Mean values were compared using analysis of variance followed by post hoc test (Bonferroni). (* Significantly different from control, ${ }^{* *}$ significantly different from diabetic.)

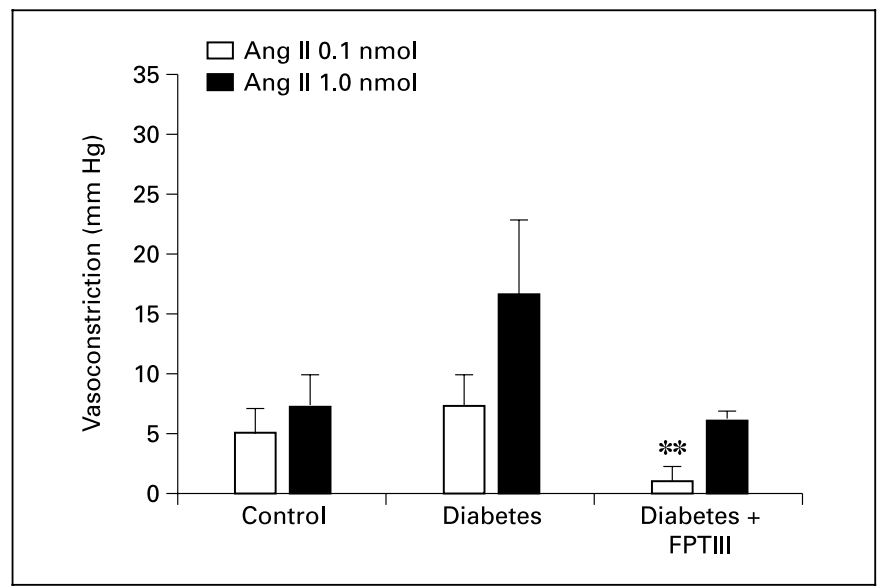

Fig. 3. Ang II-induced vasoconstriction $(0.1,1.0$ and $10 \mathrm{nmol})$ in the perfused mesenteric vascular bed of control, diabetic and FPTIIItreated diabetic rats (mean $\pm \mathrm{SE}, \mathrm{n}=8-10$ ). Mean values were compared using analysis of variance followed by post hoc test (Bonferroni). (** Significantly different from diabetic.)

The vasoconstrictor response to Ang II (0.1 and 1.0 nmol) was increased in the diabetic perfused mesenteric vascular bed compared to the control non-diabetic rats (fig. 3). However, the increase in the vasoconstrictor response did not reach the level of significance. Treatment of the diabetic rats with FPTIII significantly attenuated Ang-II-induced vasoconstriction at the dose of $0.1 \mathrm{nmol}$.

Med Princ Pract 2004;13:57-62 


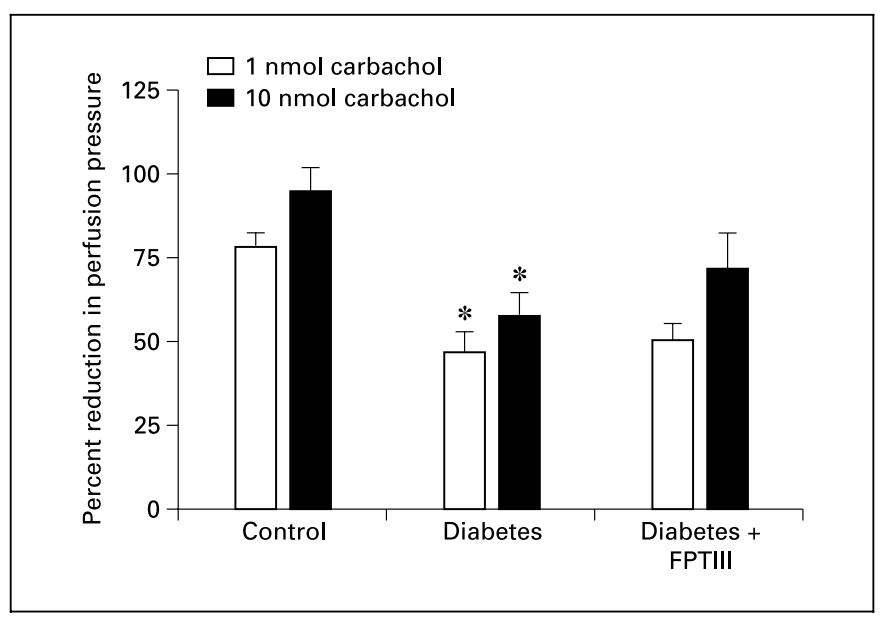

Fig. 4. Carbachol-induced vasodilation (1 and $10 \mathrm{nmol})$ in the perfused mesenteric vascular bed of control, diabetic and FPTIIItreated diabetic rats (mean $\pm \mathrm{SE}, \mathrm{n}=8-10$ ). Mean values were compared using analysis of variance followed by post hoc test (Bonferroni). (* Significantly different from control.)

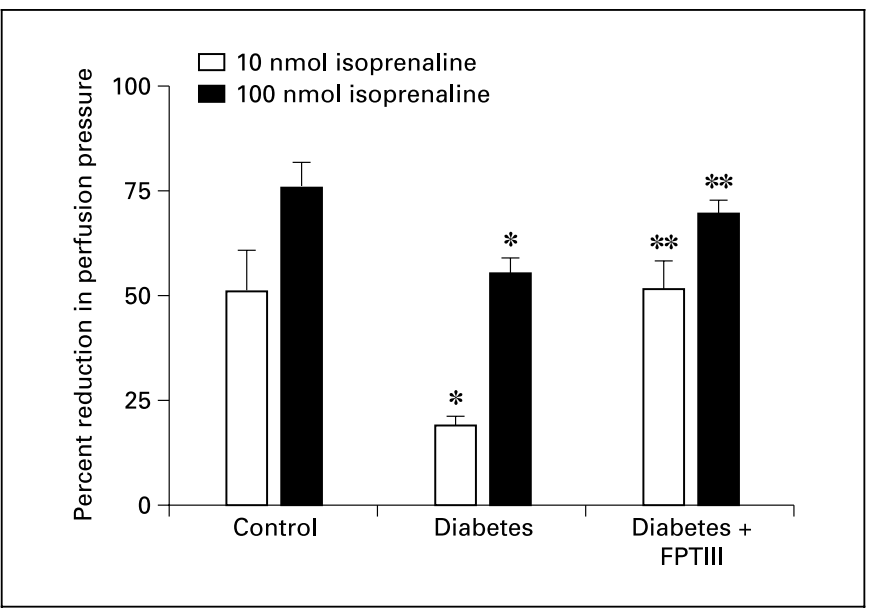

Fig. 6. Isoprenaline-induced vasodilation (10 and $100 \mathrm{nmol})$ in the perfused mesenteric vascular bed of control, diabetic and FPTIIItreated diabetic rats (mean $\pm \mathrm{SE}, \mathrm{n}=8-10$ ). Mean values were compared using analysis of variance followed by post hoc test (Bonferroni). (* Significantly different from control, ${ }^{* *}$ significantly different from diabetic.)

\section{Vasodilation Studies}

The vasodilator response to carbachol was significantly reduced in the perfused mesenteric vascular bed from STZ-diabetic rats to $42.7 \pm 6.8$ and $59.2 \pm 5.5 \%$ compared to $79.2 \pm 4.5$ and $99.8 \pm 5.3 \%$ in the control rats, at 1 and $10 \mathrm{nmol}$, respectively (fig. 4). Although there was

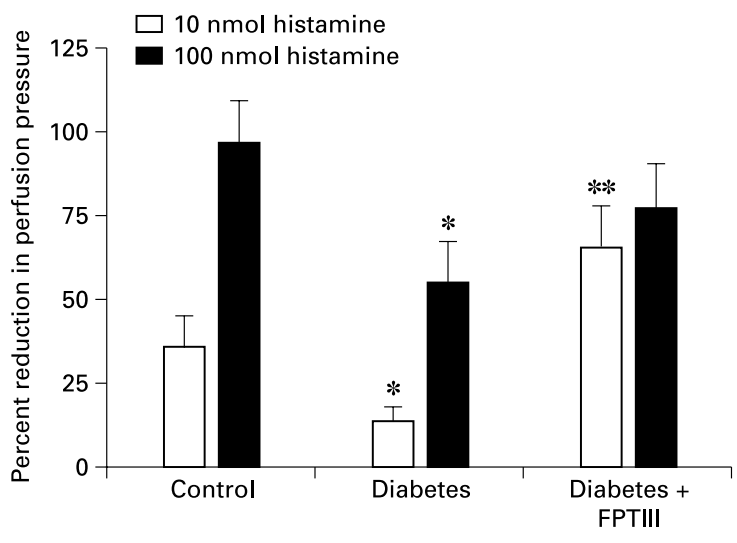

Fig. 5. Histamine-induced vasodilation $(10$ and $100 \mathrm{nmol})$ in the perfused mesenteric vascular bed of control, diabetic and FPTIIItreated diabetic rats (mean $\pm \mathrm{SE}, \mathrm{n}=8-10)$. Mean values were compared using analysis of variance followed by post hoc test (Bonferroni). (* Significantly different from control, ${ }^{* *}$ significantly different from diabetic.)

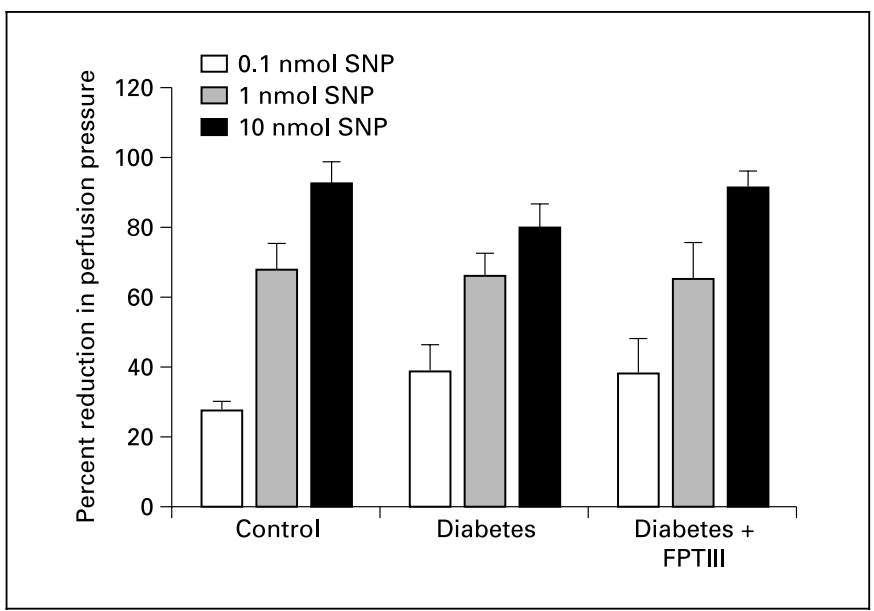

Fig. 7. SNP-induced vasodilation $(0.1,1.0$ and $10 \mathrm{nmol})$ in the perfused mesenteric vascular bed of control, diabetic and FPTIIItreated diabetic rats (mean $\pm \mathrm{SE}, \mathrm{n}=8-10$ ). Mean values were compared using analysis of variance followed by post hoc test (Bonferroni).

some tendency to improve carbachol-induced vasodilator response, FPTIII treatment of the diabetic rats did not result in a significant reversal of carbachol-induced vasodilator response.

The vasodilator response to histamine $(100 \mathrm{nmol})$ was significantly reduced in the perfused mesenteric vascular bed from STZ-diabetic rats to $53.9 \pm 10.5 \%$ compared to 
$98.5 \pm 13.3 \%$ in the control rats (fig. 5). FPTIII treatment of the diabetic rats resulted in a significant reversal of histamine-induced vasodilator response, giving $66.2 \pm$ $12.6 \mathrm{~mm} \mathrm{Hg}$ at the dose of $10 \mathrm{nmol}$.

Isoprenaline-induced vasodilation was significantly reduced in the perfused mesenteric vascular bed from STZdiabetic rats, to $19.2 \pm 2.3$ and $55.7 \pm 3.2 \%$, compared to $51.6 \pm 9.1$ and $76.4 \pm 5.5 \%$ in the control rats at doses of 10 and 100 nmol, respectively (fig. 6). Treatment of the diabetic rats with FPTIII significantly potentiated isoprenaline-induced vasodilator response to $52.4 \pm 6.3$ and $70 \pm 3 \%$ at doses of 10 and $100 \mathrm{nmol}$, respectively.

The vasodilator response to SNP was not significantly different in the four groups studied. Neither diabetes, nor treatment of the diabetic rats with FPTIII, affected SNPinduced vasodilation (fig. 7).

\section{Discussion}

Diabetes mellitus affects the structural and functional integrity of many organ systems including the cardio-vasculature. Despite conflicting reports on whether the vascular reactivity is enhanced or attenuated for a given vasoactive agonist, diabetes-induced abnormalities in vascular function are now well established [14-17]. In the perfused mesenteric vascular bed from rats with STZ-induced diabetes used in the present study, we observed an exaggerated response to vasoconstrictors Ang II, NE and ET-1, and an attenuated response to the vasodilators carbachol, histamine and isoprenaline. In this study we have shown that inhibition of the downstream signalling molecule RasGTPase, by the Ras farnesyltransferase inhibitor FPTIII, normalized the altered vascular reactivity observed with the vasoconstrictors NE, ET-1 and Ang II, and to the vasodilators carbachol, histamine and isoprenaline in diabetic animals. Inhibition of Ras-GTPase in the control animals did not have any significant effect on the vascular reactivity. Thus, our findings suggest that Ras-GTPase is involved in signalling pathways leading to abnormal vascular reactivity in diabetes. This conclusion is supported by our previous observations that Ras-GTPase activity is elevated during development of hypertension, that treatment with FPTIII prevented elevations in the Ras-GTPase activity and attenuated development of hypertension and related end-organ damage [8-9] and that noradrenaline-induced phospholipase D activation in vascular smooth muscle cells is mediated by Ras-GTPase which can be inhibited by FPTIII in a manner similar to inhibition by treatment of cells with dominant negative Ras [12].

Role of Ras-GTPase in Diabetes-Induced

Vascular Dysfunction
Activation of G-protein-coupled receptors (GPCR) and receptor tyrosine kinases by vasoactive factors such as growth factors and hormones like Ang II, histamine, opiates, endothelins and catecholamines can lead to development of vascular dysfunction. Activation of GPCR and receptor tyrosine kinases leads to activation of signal transduction factors such as protein kinase $\mathrm{C}(\mathrm{PKC})$ and transcription factors such as nuclear factor $-\kappa \mathrm{B}(\mathrm{NF}-\kappa \mathrm{B})$ in the vasculature through activation of Ras-GTPase. Increased PKC activity is a key mediator of diabetic pathologies and its inhibition has been shown to prevent the development of vascular dysfunction in diabetes [18-20]. $\mathrm{NF}-\kappa \mathrm{B}$ regulates many genes that are involved in vascular physiopathology of hypertension and diabetes [21]. This suggests that the beneficial effects observed with FPTIII in our study may, in part, be due to inhibition of RasGTPase-mediated PKC and NF- $\kappa \mathrm{B}$ activation.

Ang II is also implicated in development of vascular dysfunction in diabetes. Inhibitors of Ang II formation and Ang II receptor blockers are indicated for treatment of diabetic subjects suffering from cardiovascular complications. Angiotensin receptors mediate important cardiovascular responses such as vasoconstriction, vascular remodelling and cell survival/death and evoke several signals such as calcium mobilization, activation of protein kinases like PKC and MAPK and activation of nuclear transcription factors such as $\mathrm{NF}-\kappa \mathrm{B}$, signal transducer and activator transcription factor and activator protein-1 [22]. Since Ras-GTPase is known to mediate actions resulting from angiotensin receptor activation, it is likely that the effects seen with FPTIII in this study may be partly due to prevention of Ang II contribution to development of vascular dysfunction in diabetes.

Hyperglycaemia attenuates endothelium-dependent vasodilation in healthy subjects. It has been shown that hyperglycaemia impairs endothelial function, in part, via PKC activation [18]. The attenuated response to the vasodilators carbachol, histamine and isoprenaline observed in diabetes may additionally be explained by a vasoconstrictor input due to elevated PKC in the hyperglycaemic state, thereby providing a countersignal to the agonistinduced vasodilation. The subsequent normalization of the attenuated vasodilator response to carbachol and histamine by FPTIII may therefore be explained by removal of this countersignal by the inhibition of downstream signalling of PKC through activation of Ras-GTPase. Interestingly, response to SNP was the same in all groups studied, indicating that the responsiveness of vascular smooth muscle cells to nitric oxide was not altered in diabetes. This observation with SNP supports the hypothesis that

Med Princ Pract 2004; 13:57-62 
endothelial dysfunction is the major cause of vascular complications in diabetes and that activation of signal transduction pathways involving Ras-GTPase contributes to the dysfunction of the endothelium. This is in agreement with a recent observation where it was shown that treatment with FPTIII prevents deterioration in endothelial function due to balloon angioplasty [10].

\section{Conclusion}

We have shown that treatment with FPTIII produced a significant normalization of the altered agonist-induced vasoconstrictor and vasodilator responses in hyperglycaemic animals without affecting the weight loss that nor- mally occurs during diabetes. Thus, our data suggest that signalling via Ras-GTPase pathway is an essential component in the development of vascular dysfunction in hyperglycaemia. Furthermore, potential strategies aimed at modifying actions of signal transduction pathways involving Ras-GTPase may represent promising novel approaches for the treatment of vascular complications in diabetes.

\section{Acknowledgement}

This work was supported by a grant from Kuwait University Research Administration (project number MR02/02). The authors would like to thank Mr. A. Cherian for his technical support.

\section{References}

1 Garcia MJ, McNamara PM, Gordon T, Kannel WB: Morbidity and mortality in diabetics in the Framingham population: Sixteen year follow-up study. Diabetes 1974;23:105-111.

2 Jarrett RJ: Cardiovascular disease and hypertension in diabetes mellitus. Diabetes Metab Rev 1989;5:547-558.

3 Abebe W, Harris KH, MacLeod KM: Enhanced contractile responses of arteries from diabetic rats to $\alpha_{1}$-adrenoceptor stimulation in the absence and presence of extracellular calcium. J Cardiovasc Pharmacol 1990;16:239_ 248.

4 Mayhan WG, Irvine SD, Sharpe GM: Constrictor responses of resistance arterioles during diabetes mellitus. Diabetes Res Clin Pract 1999;44:147-156

5 Oyama Y, Kawasaki H, Hattori Y, Kanno M: Attenuation of endothelium-dependent relaxation in aorta from diabetic rats. Eur J Pharmacol 1986;132:75-78.

6 Kamata K, Miyata N, Kasuya Y: Impairment of endothelium-dependent relaxation and changes in levels of cyclic GMP in aorta from streptozotocin-induced diabetic rats. Br J Pharmacol 1989;97:614-618

7 Makino A, Ohuchi K, Kamata K: Mechanisms underlying the attenuation of endothelium-dependent vasodilatation in the mesenteric arterial bed of the streptozotocin-induced diabetic rat. Br J Pharmacol 2000;13:549-556.

8 Muthalif MM, Benter IF, Khandekar Z, Gaber L, Estes A, Malik S, Parmentier JH, Manne V, Malik KU: Contribution of Ras-GTPase/MAP kinase and cytochrome P450 metabolites to deoxycorticosterone-salt-induced hypertension. Hypertension 2000;35:457-463.
9 Muthalif MM, Karzoun NA, Gaber L, Khandekar Z, Benter IF, Saeed AE, Parmentier JH, Estes A, Malik KU: Ang II-induced hypertension: Contribution of Ras-GTPase/mitogen-activated protein kinase and cytochrome P450 metabolites. Hypertension 2000;36:604-609.

10 Work LM, McPhaden AR, Pyne NJ, Pyne S, Wadsworth RM, Wainwright CL: Short-term local delivery of an inhibitor of Ras farnesyltransferase prevents neointima formation in vivo after porcine coronary balloon angioplasty. Circulation 2001;104:1538-1543.

11 Gibbs JB, Oliff A: The potential of farnesyltransferase inhibitors as cancer chemotherapeutics. Annu Rev Pharmacol Toxicol 1997; 37:143-166.

12 Muthalif MM, Parmentier JH, Benter IF, Karzoun N, Ahmed A, Khandekar Z, Adl MZ, Bourgoin S, Malik KU: Ras/mitogen-activated protein kinase mediates norepinephrine-induced phospholipase $\mathrm{D}$ activation in rabbit aortic smooth muscle cells by a phosphorylation-dependent mechanism. J Pharmacol Exp Ther 2000;293:268-274

13 Muthalif M, Karzoun N, Benter IF, Gaber L, Ljuca F, Uddin MR, Khandekar Z, Estes A, Malik KU: Functional significance of activation of calcium/calmodulin-dependent protein kinase II in angiotensin II-induced vascular hyperplasia and hypertension. Hypertension 2002;39:704-709.

14 Head RJ, Longhurst PA, Panek RL, Stitzel RE: A contrasting effect of the diabetic state upon the contractile responses of aortic preparations from rat and rabbit. Br J Pharmacol 1987;91: 275-286.

15 Bhardwaj R, Moore PK: Increased vasodilator response to acetylcholine of renal blood vessels from diabetic rats. J Pharm Pharmacol 1988; 40:739-742.
16 Kamata K, Hosokawa M: Endothelial dysfunction in the perfused kidney from the streptozotocin-induced diabetic rat. Res Commun Mol Pathol Pharmacol 1997;96:57-70.

17 Makino A, Kamata K: Possible modulation by endothelin-1, nitric oxide, prostaglandin $\mathrm{I}_{2}$ and thromboxane $A_{2}$ of vasoconstriction induced by an $\alpha$-agonist in mesenteric arterial bed from diabetic rats. Diabetologia 1998;41:14101418 .

18 Beckman JA, Goldfine AB, Gordon MB, Garrett LA, Creager MA: Inhibition of protein kinase $\mathrm{C}$ beta prevents impaired endotheliumdependent vasodilation caused by hyperglycemia in humans. Circ Res 2002;90:5-7.

19 Booth G, Stalker TJ, Lefer AM, Scalia R: Mechanisms of amelioration of glucose-induced endothelial dysfunction following inhibition of protein kinase $\mathrm{C}$ in vivo. Diabetes 2002;51:1556-1564.

20 Koya D, Haneda M, Nakagawa H, Isshiki K, Sato H, Maeda S, Sugimoto T, Yasuda H, Kashiwagi A, Ways DK, King GL, Kikkawa R: Amelioration of accelerated diabetic mesangial expansion by treatment with a PKC beta inhibitor in diabetic $\mathrm{db} / \mathrm{db}$ mice, a rodent model for type 2 diabetes. FASEB J 2000;14:439-447.

21 Hattori Y, Hattori S, Sato N, Kasai K: Highglucose-induced nuclear factor $\kappa \mathrm{B}$ activation in vascular smooth muscle cells. Cardiovasc Res 2000;46:188-197.

22 Ruiz-Ortega M, Lorenzo O, Ruperez M, Konig $\mathrm{S}$, Wittig B, Egido J: Angiotensin II activates nuclear transcription factor $\kappa \mathrm{B}$ through $\mathrm{AT}_{1}$ and $\mathrm{AT}_{2}$ in vascular smooth muscle cells molecular mechanisms. Circ Res 2000;86:12661272 . 